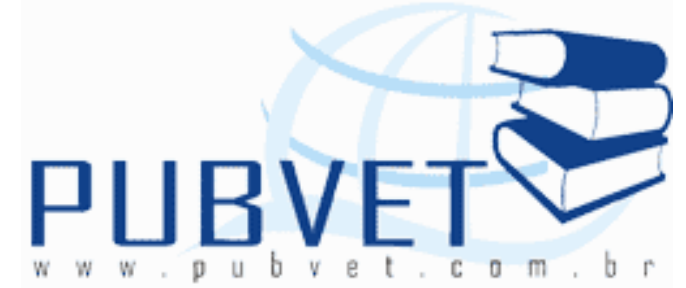

PUBVET, Publicações em Medicina Veterinária e Zootecnia.

\title{
Composição de ácidos graxos na carne de cordeiro em confinamento
}

Luis Gustavo Castro Alves ${ }^{1}$, Alexandre Rodrigo Mendes Fernandes ${ }^{2}$; José Carlos da Silveira Osório ${ }^{3}$, Maria Teresa Moreira Osório³; Keni Eduardo Zanoni Nubiato ${ }^{1}$, Camila Magalhães da Cunha ${ }^{1}$, Thatiane da Cunha Cornélio ${ }^{1}$, Ana Paula Catalano Neto ${ }^{1}$

${ }^{1}$ Mestrando(a) do Programa de Pós Graduação em Zootecnia Universidade Federal da Grande Dourados,UFGD, Dourados MS, bolsista Capes;

${ }^{2}$ Docente do Curso de Pós Graduação em Zootecnia - UFGD.

3 Professor(a) Visitante Nacional Sênior da Universidade Federal da Grande Dourados- UFGD - CAPES; Bolsista Produtividade do CNPq.

\section{Resumo}

O objetivo da revisão foi avaliar a composição dos ácidos graxos da carne de cordeiros em confinamento, buscando nos resultados de pesquisas realizadas no Brasil, embasamento para as considerações. Foram abordadas as alternativas de alimentos utilizados na dieta dos cordeiros e possíveis efeitos sobre a qualidade de sua carne. Considerando que a carne de ovinos jovens é um alimento funcional com propriedades nutracêuticas, destinada a consumidores exigentes nos benefícios à saúde e na satisfação sensorial. Por serem poucos os dados conclusivos comparativos da composição de ácidos graxos da carne de cordeiros, as considerações devem ser tomadas com os devidos cuidados e servem para uma orientação de futuras pesquisas e para o 
ALVES, L.G.C. et al. Composição de ácidos graxos na carne de cordeiro em confinamento. PUBVET, Londrina, V. 6, N. 32, Ed. 219, Art. 1455, 2012.

consumidor que busca por alimento de qualidade sem preconceitos fora da ciência. Conclui-se que a composição dos ácidos graxos da carne de ovinos jovens pode ser modificada pela adequada dieta recebida pela alimentação fornecida durante o período de confinamento.

Palavras Chaves: alimentação, ovinos, propriedades nutracêuticas, sistema de terminação

\title{
Fatty acid composition in the meat of feedlot lambs
}

\begin{abstract}
The aim of the review was to evaluate the fatty acid composition of lamb meat in feedlot, seeking the results of search conducted in Brazil evidence of the considerations. Will discuss the alternatives of foods used in the diet of lambs and possible effects on the quality of its meat. Whereas the meat of young sheep is a functional food with nutraceutical properties for consumers demanding us benefits to health and sensory satisfaction. Being they there few conclusive data comparing the fatty acid composition of lamb meat, considerations should be taken with due care and serve as an orientation for future research and for consumer search for quality food unprejudiced outside science. It is concluded that the fatty acid composition of meat from young sheep may be modified by proper diet received by the food provided during the period of feedlot.
\end{abstract}

Keywords: finishing system, food, nutraceutical properties, sheep

\section{Introdução}

Recentemente nota-se o interesse do consumidor em conhecer o produto colocado a sua mesa, buscando alimentos saudáveis e de qualidade. Assim, as carnes de melhores propriedades nutracêuticas passaram a ter preferência por apresentarem propriedades funcionais e benéficas à saúde humana. Dentre as 
ALVES, L.G.C. et al. Composição de ácidos graxos na carne de cordeiro em confinamento. PUBVET, Londrina, V. 6, N. 32, Ed. 219, Art. 1455, 2012.

carnes vermelhas, a carne dos ovinos destaca-se por suas características organolépticas e por seu alto valor nutritivo e funcional.

O enfoque na pesquisa em relação à composição da carne, no que diz respeito aos ácidos graxos, tem se fundamentado em diagnosticar com precisão a quantidade existente do perfil destes componentes no produto final (carne). Entretanto, a composição de ácidos graxos nos produtos oriundos de ruminantes é complexa e particular, em razão, da síntese ruminal, bem como o processo de biohidrogenação que ocorre neste ambiente mediado por bactérias.

A determinação do perfil de ácidos graxos é de grande relevância, particularmente no que diz respeito a determinar o teor de ácidos graxos essenciais, saturados, monoinsaturados, poliinsaturados e, mais recentemente os ácidos linoléicos conjugados (CLA), estes são um grupo que exibem vários possíveis efeitos sobre a saúde humana.

É notório que o perfil de ácidos graxos pode ser influenciado pela dieta a qual o animal é submetido, cuja manipulação pode ser feita mediante a inclusão de fontes lipídicas, manipulação da relação volumoso:concentrado e inclusão de aditivos. Porém, exigências por quantidades maiores de carne, coloca em dúvida o sistema de criação e terminação dos animais, contudo, deve se atentar para busca maciça nas descobertas a respeito da composição e das propriedades na carne de animais terminados em confinamento.

No entanto, como alternativa do sistema de produção da ovinocultura, o confinamento se apresenta como ferramenta que pode proporcionar lotes homogêneos em menor espaço de tempo. Neste sentido, o objetivo da revisão foi avaliar a concentração dos principais ácidos graxos na carne de cordeiros terminados em confinamento e seus possíveis efeitos na saúde humana. 
ALVES, L.G.C. et al. Composição de ácidos graxos na carne de cordeiro em confinamento.

PUBVET, Londrina, V. 6, N. 32, Ed. 219, Art. 1455, 2012.

\section{A composição de ácidos graxos e a saúde humana}

A carne contém uma ampla variedade de lipídios, sendo que estão presentes na carne ovina na forma de gordura subcutânea, gordura intramuscular (dentro das fibras musculares ou células, principalmente na forma de fosfolipídios e alguns triglicerídeos), gordura intermuscular, composta principalmente de triglicerídeos.

A carne dos animais mais jovens contém menor proporção de gordura em comparação com a dos adultos, visto que, os jovens são menos predispostos ao acúmulo de gordura subcutânea e intermuscular. Quanto ao sexo, as fêmeas têm maior predisposição que os machos inteiros para o acúmulo de gordura, já os animais castrados tendem a acumular mais gordura que os machos inteiros (Azevedo, 2004).

Em relação à composição dos ácidos graxos mais encontrados na carne ovina, tem se os ácidos graxos saturados: mirístico (C 14:0), palmítico (C 16:0) e esteárico (C 18:0); os monoinsaturados são o palmitoléico (C 16:1) e oléico (C 18:1) e os poliinsaturados são o linoléico (C 18:2 $\omega 6$ ), linolênico (C18:3 w3) e araquidônico (Monteiro, 1998). Na tabela 1, ilustra a classificação dos ácidos graxos em função da estrutura e funcionalidade.

Tabela 1. Classificação dos ácidos graxos em função da estrutura e funcionalidade

\begin{tabular}{|c|c|c|c|}
\hline \multicolumn{2}{|c|}{ Classificação estrutural } & \multicolumn{2}{|c|}{ Classificação funcional } \\
\hline Saturados & $\begin{array}{l}\mathrm{C} 4: 0 \text { a C10:0 C12:0, C14:0, } \\
\mathrm{C} 16: 0, \mathrm{C} 18: 0\end{array}$ & Hipercolesterolêmios & $\begin{array}{l}\mathrm{C} 12: 0, \mathrm{C} 14: 0 \\
\mathrm{C} 16: 0\end{array}$ \\
\hline Monoinsaturados & $\mathrm{C} 14: 1, \mathrm{C} 16: 1, \mathrm{C} 18: 1, \mathrm{C} 20: 1$ & Neutro & $\begin{array}{l}\mathrm{C} 4: 0 \text { a } \mathrm{C} 10: 0 \\
\mathrm{C} 18: 0\end{array}$ \\
\hline Poliinsaturados & $\mathrm{C} 18: 2, \mathrm{C} 18: 3, \mathrm{C} 20: 3, \mathrm{C} 22: 5$ & $\begin{array}{l}\text { Hipocolesterolêmios } \\
\text { Outros }\end{array}$ & $\begin{array}{l}\text { C18:1 c9, } \\
\text { C18:2 c9, c12, } \\
\text { C18:3 } \\
\text { c9,c12,c15 } \\
\text { C15 :0, C17:0 } \\
\text { Ramificados }\end{array}$ \\
\hline
\end{tabular}

Fonte: Adaptado de Bessa (1999) 
ALVES, L.G.C. et al. Composição de ácidos graxos na carne de cordeiro em confinamento. PUBVET, Londrina, V. 6, N. 32, Ed. 219, Art. 1455, 2012.

A ingestão diária de carne (100g/dia) é capaz de suprir a maior parte das exigências em proteínas e ácidos graxos essenciais para o homem. No entanto, a gordura presente na carne dos ruminantes difere substancialmente de outros animais monogástricos, por estar relacionada com o maior teor de ácidos graxos saturados e a baixa concentração de poliinsaturados (Bessa, 1999).

Existe, atualmente, uma grande importância na quantidade e composição das gorduras da carcaça, pois foi verificado que as gorduras com alto teor de ácidos graxos monoinsaturados devem ser as preferidas para o consumo, pois aumentam os níveis de HDL-colesterol (lipoproteína de alta densidade) e diminuem os níveis de LDL-colesterol (lipoproteína de alta densidade) Osório et al.(2006).

A premissa de que a carne dos ruminantes é nociva à saúde se baseia no fato de que a gordura saturada encontrada nesse alimento eleva o nível de colesterol, que aumenta o risco de obstrução das artérias podendo levar ao desenvolvimento de doenças cardiovasculares e até a morte.

Mesmo que a relação entre consumo de gorduras saturadas e problemas vasculares não sejam conclusivas, de acordo com Wood et al.(2003), nos últimos anos houve um interesse crescente em desenvolver estratégias de manejo nutricional dos animais visando melhorar a composição em ácidos graxos da carne e, desta forma, diminuir sua implicação em problemas de saúde.

Os ácidos graxos são compostos que conferem aos lipídeos as propriedades nutricionais e as características físico-químicas responsáveis pelos atributos sensoriais e pela conservação da carne.

Portanto, são nutrientes fundamentais utilizados pelo organismo em diversas funções: melhora da resposta imunológica Albers et al. (2003), ação anti-inflamatória e anticarcinogênica IP et al. (2002), principalmente contra o câncer de estômago, mama, cólon e próstata Ha et al.(1987), e entre outras atividades, como antioxidantes, antidiabética, emagrecedora, cardioprotetora, 
ALVES, L.G.C. et al. Composição de ácidos graxos na carne de cordeiro em confinamento. PUBVET, Londrina, V. 6, N. 32, Ed. 219, Art. 1455, 2012.

e na regulação da expressão de genes que codificam várias enzimas que participam no metabolismo de lipídios e carboidratos.

\section{1 Ácidos Graxos de grande importância}

\subsection{1 Ácidos graxos ômega-6 e ômega-3}

Os ácidos graxos das famílias $\omega 6$ e $\omega 3$ têm sido alvos de inúmeros estudos nas últimas décadas, os quais esclareceram muitas das suas funções no organismo humano e as reações envolvidas na sua formação, a partir dos ácidos linoléico - (18:2) $\omega$-6 e alfa-linolênico - (18:3) $\omega$-3. Classificam-se por serem considerados essenciais, pois o organismo não os produz, devendo ser ingeridos pela alimentação diária. Portanto a carne ovina pode contribuir para o equilíbrio dietético na relação de ácidos graxos $\omega 6$ e $\omega 3$.

Pesquisas mais recente demonstram que a adequação do balanço dietético dos ácidos graxos das famílias $\omega 6$ e $\omega 3$ pode ser mais importante do que as relações entre o total de ácidos graxos saturados e insaturados ingeridos. Conforme descrito por Martin et al. (2006), os valores mostram uma tendência de convergência da razão entre os ácidos graxos $\omega 6: \omega 3$ para o intervalo de $4: 1$. Por outro lado, dietas com relações inferiores a $1: 1$ não são recomendadas por inibirem a transformação do ácido linoléico em ácidos graxos polinsaturados de cadeia muito longa. Na tabela 2 apresenta a relação existente entre $\omega 6: \omega 3$ no músculo Longissimus lumborum de cordeiro de acordo com dados encontrados na literatura.

Ferrão (2006) avaliando o efeito da relação concentrado:volumoso (100:0; 75:25, 50:50) nas amostras de carne de ovinos Santa Inês, encontrou para relação $\omega 6 / \omega 3$ valores elevados nas diferentes dietas, mostrando uma tendência em se afastar da recomendação considerada nutricionalmente adequada. 
ALVES, L.G.C. et al. Composição de ácidos graxos na carne de cordeiro em confinamento. PUBVET, Londrina, V. 6, N. 32, Ed. 219, Art. 1455, 2012.

Tabela 2 - Relação entre os ácidos graxos $\omega 6: \omega 3$ no músculo Longissimus lumborum de cordeiro

\begin{tabular}{|c|c|}
\hline Autores & $\mathbf{\omega 6 : \boldsymbol { \omega }}$ \\
\hline Kaiser et al., 2011 & 2,43 \\
\hline Esner et al., 1996 & 1,3 \\
\hline Maia, 2011 & 3,27 \\
\hline Pelegrini, 2007 & $10,29-13,04$ \\
\hline Ferrão, 2006 & $0,68-2,08$ \\
\hline Wachira et al., 2002 & $1,85-5,47$ \\
\hline Santos-Silva et al., 2002
\end{tabular}

\subsection{2 Ácido Linoléico Conjugado (CLA)}

O CLA representa uma mistura de isômeros posicionais e geométricos do ácido octadecadienóico (C18:2). Entre os vários isômeros do CLA destacam-se o C18:2 cis-9, trans-11, mais abundante na natureza, com reconhecida atividade anticarcinogênica e melhorador do sistema imunológico, como já comprovado em diferentes modelos animais e o C18:2 trans-10, cis-12, relacionado ao metabolismo de gorduras. Portanto são duas moléculas com pequenas diferenças de posição e geometria de ligação, mas com ações diversas e intensas no metabolismo animal.

Dentre os ruminantes, os ovinos destacam se pela capacidade de incorporar CLA na gordura intramuscular (marmoreio), o fato de apresentar maior quantidade neste tipo de gordura tem grande importância, pois frequentemente a gordura subcutânea e intermuscular são retiradas do músculo no momento do consumo, e a gordura intramuscular se mantém "protegida" Osório et al.(2006). Segundo Kelly et al. (1998), a suplementação com óleo de amendoim, girassol e semente de linhaça, pode ser utilizada com o objetivo de aumentar a deposição de CLA na gordura intramuscular.

Estudo realizado por Lobo (2010) encontrou valores para ácido linoléico conjugado (CLA) entre $0,42 \%$ a $1,24 \%$ e Zeola et al. (2011) avaliando sistema 
ALVES, L.G.C. et al. Composição de ácidos graxos na carne de cordeiro em confinamento. PUBVET, Londrina, V. 6, N. 32, Ed. 219, Art. 1455, 2012.

orgânico e convencional encontrou 0,69\% e 0,65\%,respectivamente. Outro dado interessante que Costa (2011) encontrou aumento de CLA em relação do nível de substituição do milho pela casca da soja, sendo que este aumento foi de 0,013 pontos percentuais de CLA para cada $1 \%$ de substituição. Sugere se que tenha ocorrido uma incompleta biohidrogenação do ácido linoléico (C18:2) pela microbiota ruminal, originando então o ácido linoléico conjugado, sendo então absorvido e depositado no músculo.

\section{Fatores que afetam a composição dos ácidos graxos}

A forragem contém alto nível de ácidos graxos linolênico (C18:3), precursor da série n-3 de ácidos graxos. O concentrado, ao contrário, tem alto teor de ácido linoléico (C18:2), precursor da série n-6 (Díaz et al., 2002). A porcentagem de ácidos graxos poliinsaturados é maior na gordura subcutânea de cordeiros terminados em confinamento, em razão da grande quantidade de concentrado ingerido, que modifica as reações bioquímicas do rúmen.

Para conseguir modificar a composição de ácidos graxos e teores de colesterol da carne de ovinos e atender a procura dos consumidores por alimento saudável, várias estratégias têm sido utilizadas, como a escolha da raça (Monteiro, 1998; Bianchi et al.,2003; Farias, 2005), sexo (Webb et al., 1994), peso ao abate (Pérez et al., 2002; Santos-Silva et al., 2002) e alimentação (Enser, et al., 1996; Wachira et al., 2002; Madruga et al., 2005; Ferrão, 2006).

\subsection{Raça}

Monteiro (2000) determinou a composição de ácidos graxos da carne de ovinos da raça Corriedale, tendo encontrado $48,84 \%$ de saturados, $34,60 \%$ de monoinsaturados, $8,35 \%$ de poliinsaturados e uma relação poliinsaturados/saturados de 0,17 . 
ALVES, L.G.C. et al. Composição de ácidos graxos na carne de cordeiro em confinamento. PUBVET, Londrina, V. 6, N. 32, Ed. 219, Art. 1455, 2012.

Os valores encontrados por Kaiser et al. (2011) afirmaram que o grupamento genético influenciou no conjunto dos hipercolesterolêmicos sendo que o grupo genético da raça nativa diferiu do grupo com cruzamento Nativa $x$ Texel e não diferiu do cruzamento Nativa x Santa Inês $(27,74 \%$ x $25,57 \%$ x $26,14 \%)$.

Banskalieva et al. (2000) e Rhee (1992) reportaram médias de ácidos graxos desejáveis (ácidos graxos monoinsaturados + ácidos graxos poliinsaturados + ácido graxo esteárico C18:0) na carne de ovinos, de 64 a 72. Madruga et al. (2005) encontraram na carne de cordeiros Santa Inês, os percentuais de ácidos graxos desejáveis que variaram de 70,27 a 72,48. Banskalieva et al. (2000) e Rhee (1992) defendem que a relação (C18:0 + C18:1) : C16:0 descreve os possíveis efeitos benéficos dos diferentes lipídios encontrados nas carnes vermelhas, com valores de 2,1 a 2,8 para a carne ovina. Madruga et al. (2005) encontraram os resultados que variaram de 2,53 a 2,76, confirmando a qualidade da fração lipídica de cordeiros Santa Inês.

O perfil de ácidos graxos encontrados em Longissimus dorsi de cordeiros resultantes do cruzamento entre as raças Ile de France $x$ Corriedale foi em maior quantidade para os ácidos graxos oléico, palmítico, esteárico (Monteiro e Shimokomaki 1997).

\subsection{Sexo}

Cardoso et al. (2011) avaliaram a composição de ácidos graxos na carne de cordeiros machos e fêmeas terminados em confinamento, verificaram a influência do sexo sobre a quantidade dos ácidos graxos linoléico e linolênico, sendo que os machos apresentaram maiores valores em relação as fêmeas $(4,46 \% \times 3,20 \%)$ para o ácido linoléico e $(0,29 \% \times 0,23 \%)$ para o ácido linolênico.

Ao avaliarem a composição de ácidos graxos na carne de cordeiros machos e fêmeas terminados em confinamento, Kaiser et al. (2011), 
ALVES, L.G.C. et al. Composição de ácidos graxos na carne de cordeiro em confinamento. PUBVET, Londrina, V. 6, N. 32, Ed. 219, Art. 1455, 2012.

verificaram influência do sexo sobre o grupo dos ácidos graxos monoinsaturados, sendo que as fêmeas apresentaram maiores valores em relação aos machos $(49,57 \% \times 47,09 \%)$, o grupo de ácidos graxos poliinsaturados foi ao contrário, os machos apresentaram maiores valores em relação às fêmeas $(7,35 \% \times 5,33 \%)$.

Velasco et al. (2000) relataram diferenças nos teores de lipídeos entre machos e fêmeas abatidos com $35 \mathrm{~kg}$ de peso corporal e Munhõz (1999) trabalhando com cordeiros machos em sistema intensivo aos 100 dias encontrou valores de ácidos graxos saturados de $47 \%$ e $52 \%$ para ácidos graxos insaturados.

\subsection{Alimentação}

A matéria-prima utilizada na composição da dieta altera a composição de ácidos graxos, mesmo que sejam isoprotéicas e isoenergéticas (Bas e MorandFehr, 2000). Os animais que recebem maior proporção de concentrado na dieta, como ocorrem em sistemas de confinamento, produz carne com maior teor de gordura, podendo interferir em suas características organolépticas, variando a composição dos ácidos graxos.

Madruga et al. (2005) trabalharam com cordeiros em confinamento avaliando três diferentes dietas, dentre o total de ácidos graxos identificados, seis ácidos graxos (C18:1, C18:0, C16:0, C18:2, C16:1 e C18:3) constituíram acima de $90 \%$ das áreas totais dos cromatogramas. O ácido oléico ( $\mathrm{C} 18: 1)$ foi o ácido graxo insaturado que mais contribuiu para o perfil dos ácidos graxos, enquanto os ácidos palmítico (C16:0) e esteárico (C18:0) contribuíram mais intensamente entre os ácidos graxos saturados.

Estudo realizado por Macedo et al. (2008) com intuito de avaliar os ingredientes nas dietas dos animais encontraram diferentes valores para utilização de farelo de soja e semente de girassol, a concentração do ácido graxo palmítico (C16:0) no farelo de soja é menor que a da semente de 
ALVES, L.G.C. et al. Composição de ácidos graxos na carne de cordeiro em confinamento. PUBVET, Londrina, V. 6, N. 32, Ed. 219, Art. 1455, 2012.

girassol, do mesmo modo que as concentrações dos ácidos graxos oléico (C18:1) e linoléico (C18:2) na semente de girassol são maiores que no farelo de soja. Ressalta-se que a porcentagem de farelo de soja diminuiu com o aumento dos níveis de semente de girassol nas dietas experimentais. Muci et al. (1992) adicionaram $5 \%$ de óleo de girassol em dietas para ovinos e observaram aumento da porcentagem de C18:1 e C18:2 em amostras do músculo Longissimus lumborum e ainda verificaram uma redução no teor de colesterol da carne.

O valor encontrado para relação ácidos graxos poliinsaturados:ácidos graxos saturados em cordeiros terminados em confinamento foi $(0,14)$ de acordo com Lobo (2010), valor próximo ao encontrado por Yamamoto (2006) que encontrou na terminação de cordeiros valores $(0,10$ a 0,12$)$ é menor que a recomendada para uma dieta saudável. De acordo com Wood et al. (2003), esta relação na dieta deve ser acima de 0,4, e como em algumas carnes essa relação está ao redor de 0,1 , seu consumo tem sido relacionado a um desbalanço na ingestão de ácidos graxos.

A relação ácidos graxos poliinsaturados:ácidos graxos monoinsaturados encontrado por Kaiser et al. $(2011)$ foi de $(0,15)$ próximo ao valor encontrado por Madruga et al. $(2005)$ de $(0,10)$, na qual os mesmos autores encontraram para relação ácidos graxos monoinsaturados:ácidos graxos saturados os mesmos valores $(1,03)$.

A relação ácidos graxos monoinsaturados:ácidos graxos saturados encontrado por Madruga et al. (2005) foram de 0,89\% a 1,08\% próximos aos encontrados por Kaiser et al. (2011) foram de $1,02 \%$ a $1,11 \%$ e aos encontrados por Maia (2011) variaram 1,09\% a 1,14\%.

Rodrigues et al. (2010) encontraram que com a inclusão de polpa cítrica em substituição ao milho na ração de cordeiros em confinamento ocasiona aumento linear na concentração de ácido linolênico (C18:3). No nível de 33\% de substituição ao milho, a utilização de polpa cítrica na dieta aumenta a 
ALVES, L.G.C. et al. Composição de ácidos graxos na carne de cordeiro em confinamento. PUBVET, Londrina, V. 6, N. 32, Ed. 219, Art. 1455, 2012.

concentração de ácido linoléico conjugado, mas não altera a concentração total de ácidos graxos saturados, monoinsaturados e poliinsaturados.

Maia (2011) avaliando o efeito de adição de óleos na dieta de cordeiros confinados concluiu que a adição de $3 \%$ de óleos de canola e girassol promoveram melhor composição de ácidos graxos sem comprometer as características de carcaça e composição físico-quimica do músculo longissimus dorsi, comprovando que óleos com alta proporção de ácidos graxos insaturados podem ser adicionados em dietas de ruminantes proporcionando benefícios a qualidade do produto final.

\section{Conclusão}

A terminação de cordeiros em confinamento no aspecto do perfil de ácidos graxos essenciais da carne é válida, sendo que adequação da nutrição aos animais podem proporcionar melhores resultados nutracêuticos ao consumidor.

\section{Referências Bibliográficas}

ALBERS, R.; VAN DER WIELEN, R.P.; BRINK, E.J.; HENDRIKS, H.F.; DOROVSKATARAN,V.N.; MOHEDE, I.C. Effects of cis- 9, trans-11 and trans-10, cis-12 conjugated linoleic acid (CLA) isomers on immune function in healthy men. European Journal of Clinical Nutrition, v.57, n.4, p.595-603. 2003.

AZEVEDO, A.P.R., O valor nutricional da carne. Revista Nacional da Carne. Edição n 327, maio de 2004. Disponível em: <www.dipemar.com.br/carne/editantes.htm>. Acesso em: 01 jul.2005.

BANSKALIEVA, V.; SAHLU, T.; GOETSCH, A.L. Fatty acid composition of goat muscles and fat depots - a review. Small Ruminant Research, v.37, p.255-268, 2000.

BAS, P.; MORAND-FEHR, P. Effect of nutritional factors on fatty acid composition of lamb fat deposits. Livestock Production Science, v.64, p.61-79, 2000.

BESSA, R.J.B. Revalorização nutricional das gorduras dos ruminantes. In: SYMPOSIUM EUROPEO - ALIMENTACIÓN EM EL SIGLO XXI, Badajoz, 1999. Anais... Badajoz, 1999. p.283313. 
BIANCHI, G; GARIBOTTO, G.; BENTANCUR, O. Fatty acid composition of m.longissimus dorsi in pure and crossbred lambs in grazing systems. In: INTERNATIONAL CONGRESS OF MEAT SCIENCE AND TECHNOLOGY, v.49, 2003, Campinas. Procedings... Campinas, SP: CTC/ITAL, p.175-176. 2003.

CARDOSO, C.C.R; FERNANDES, A.R.M.; KAISER, F.; ARAGÃO, G.M.; ALVES, L.G.C. Composição de ácidos graxos na carne de cordeiros terminados em confinamento. In: Encontro de Ensino, Pesquisa e Extensão- ENEP, Dourados,2011.

COSTA, L.S.; Composição e correlação de ácidos graxos na carne de cordeiros alimentados com dietas contendo casca de soja. Dissertação- Itapetinga-BA: Universidade Estadual do Sudoeste da Bahia, 68 fl. 2011.

DÍAZ, M.T.; VELASCO, S.; CAÑEQUE, V. LAUSURICA, S.; RUIZ DE HUIDOBRO, F.; PÉREZ, C.; GONZÁLEZ, J. MANZANARES, C. Use of concentrate or pasture for fattening lambs and its effect on carcass and meat quality. Small Ruminant Research, v.43, p.257-268, 2002.

ENSER M., HALLET K., HEWITT G.A., FURSEY J., WOOD J.D., Fatty acids content and composition of English beef, lamb and pork at retail. Meat Science, v 42,n 4, p. 443-456, 1996

FARIAS, P.B. Efeito de diferentes grupos genéticos sobre parâmetros quantitativos e qualitativos da carne de cordeiros. 62p. Dissertação (Mestrado em Ciência dos Alimentos). Universidade Federal de Lavras, Lavras, MG. 2005.

FERRÃO, S.P.B. Características morfométricas, sensoriais e qualitativas da carne de Cordeiros, Tese Doutorado, UFLA, 175p.: Il, Lavras: UFLA, 2006.

HA, Y.L.; GRIMM, N.K.; PARIZA, M.W. Oxford Journals,Life Sciences \& Medicine, Carcinogenesis vol 8, pag 1881-1187, 1987.

IP, C.; DONG, Y.; IP, M.M.; BANNI, S.; CARTA, G.; ANGIONI, E.; MURRU, E.; SPADA, S.; MELIS, M.P.; SAEBO, A. Conjugated linoleic acid isomers and mammary cancer prevention. Nutrition and Cancer, v.43, n.1, p.52-8, 2002.

KAISER, F.; FERNANDES, A. R. M.; REIS, C. C. C.; VARGAS JUNIOR, F. M.; ARAGÃO, G.; CAMILO, F. R. Ácidos graxos polinsaturados e relações ômega 6 e ômega 3 na carne de cordeiros terminados em confinamento. In: Encontro de Ensino, Pesquisa e Extensão- ENEP, Dourados, 2011.

KELLY, M.L.; BERRY, J.R.; DWYER, D.A.; GRIINARI, J.M.; CHOUINARDI, P.Y.; VANAMBURGH, M.E.; BAUMAN, D.E. Dietary fatty acid sources affect conjugated linoleic acid concentrations in milk from lactating dairys cows.J.Nutr., vol.128,pg.881-885, 1998.

LOBO, A.M.B.O. Fatty acid and global gene expression profiles in Brazilian hair sheep. Viçosa: Universidade Federal de Viçosa, 2010. 93p. Tese (Doutorado em Genética e Melhoramento) Universidade Federal de Viçosa, 2010.

MACEDO, V.P.; GARCIA, C.A.; SILVEIRA, A.C., MONTEIRO, A.L.G.; MACEDO, F.A.F.; SPERS,R.C.Composições tecidual e química do lombo de cordeiros alimentados com rações contendo semente de girassol em comedouros privativos. Revista Brasileira de Zootecnia, Viçosa, v.37, n.10, 2008.

MADRUGA, M.S.; SOUSA, W.H.; ROSALES, M.D. et al. Qualidade da carne de cordeiros Santa Inês terminados com diferentes dietas. Revista Brasileira de Zootecnia, v.34, n.1, p.309-315, 2005.

MAIA, M.O.; Efeito da adição de diferentes fontes de óleo vegetal na dieta de ovinos sobre desempenho, a composição e o perfil de ácidos graxos na carne e no leite. Tese Doutorado, ESALQ, 140 p.:il Piracicaba, 2011. 
MARTIN, C.A.; ALMEIDA, V.V.; RUIZ, M.R.; VISENTAINER, J.E.L.; MATSUSHITA, M.; SOUZA, N.E.; VISENTAINER, J.V. Ácidos graxos ômega 3 e ômega 6: importância e ocorrência em alimentos. Revista de Nutrição, v.19, n.6, p. 761-770, 2006.

MONTEIRO, E.M.; SHIMOKOMAKI,M. Influência da raça no perfil dos ácidos graxos na carne de cordeiros. Congresso Brasileiro de Ciência e Tecnologia de Alimentos, 16., 1997, Rio de Janeiro. Anais... Rio de Janeiro: Sociedade Brasileira de Ciência e Tecnologia de Alimentos, v.2, p.1328-1331. 1997.

MONTEIRO, E.M. Influência do cruzamento Ile de France x Corriedale (F1) nos parâmetros de qualidade da carne de cordeiro. 1998. 99 f. Tese (Doutorado em Ciência de Alimentos) Faculdade de Ciências Farmacêuticas, Universidade de São Paulo, São Paulo,1998.

MONTEIRO, E.M. Lípideos e Parâmetros Sensoriais da Carne. Curricular Técnica n 15. Embrapa Pecuária Sul. Editora Embrapa. Bagé, RS, 2000.

MUCI, M.R.; CAPPELLO, A.R.; VONGHIA, G. et al. Change in cholesterol levels and in lipid fatty acid composition in sunflower oil fed lambs. International Journal for Vitamin and Nutrition Research, n.62, p.330-333, 1992.

MUNHÕZ, P.C. Cuaderno de La explotación de ovino.Servicio Agrario de CajaDuero. 2 ed. 1999.

OSÓRIO, M.T.M.; OSÓRIO, J.C.S.; JARDIM, R.; HASHIMOTO, J.; BONACINA, M.; ÁVILA, C.C. Qualidade nutritiva e funcional da carne ovina. In: SEMANA DA CAPRINOCULTURA E DA OVINOCULTURA BRASILEIRA, Va, SECOB, 2006, Campo Grande, MS. Anais... Campo Grande: Embrapa Caprinos Gado de Corte, 2006. CD. 32 páginas. 2006.

PELEGRINI, L.F.V.; Perfil de ácidos graxos, embutido fermentado e características da carcaça de ovelhas de descarte, TESE DE DOUTORADO, UFSM, 70 p.:Il Santa Maria,2007.

PEREZ, J. R. O. et al. Efeito do peso ao abate de cordeiros Santa Inês e Bergamácia sobre o perfil de ácidos graxos, colesterol e propriedades químicas. Revista Ciência e Tecnologia de Alimentos, v. 22, n. 1, p. 11-18, 2002.

RODRIGUES, G.H.; SUSIN, I.; PIRES, A.V.; ALENCAR, S.M.; MENDES, C.Q.; GENTIL, R.S. Perfil de ácidos graxos e composição química do músculo longissimus dorsi de cordeiros alimentados com dietas contendo polpa cítrica. R. Bras. Zootec., v.39, n.6, p.1346-1352, 2010.

SANTOS-SILVA, J.; BESSA, R. J. B.; SANTOS-SILVA, F. Effect of genotype,feeding sytem and slaughter weight on the quality of light lambs II. Fatty acid composition of meat. Livestock Production Science, New York, v.77, n.2-3,p.187-194, Nov. 2002.

VELASCO, S., LAUZURICA, S., CAÑEQUE, V., et al. Carcass and meat quality of talaverana breed sucking lambs in relation to gender and slaughter weigth. Animal Science, Penikuik, n.70, p.253-263, 2000.

WACHIRA, A. M.; SINCLAIR, L. A.; WILKINSON, R. G.; ENSER, M.;WOOD, J. D.; FISHER, A. V. Effects of dietary fat source and breed on the carcass composition, $n-3$ polyunsaturated fatty acid and conjugated linoleic acid content of sheep meat and adipose tissue. British Journal of Nutrition, London, v. 88, n.6, p.697-709, Dec. 2002.

WEBB, E.C.; CASEY, N. H.; NIEKERK VAN, W. A. Fatty acids in the subcutaneous adipose tissue of intensively SA Mutton Merino and Dorper wethers. Meat Science, Amsterdam, v.38, n.1, p.123-131, 1994.

WOOD, J.D.; RICHARDSON, G. R.; NUTE, G. R.; FISHER, A. V; CAMPO, M. M.; KASAPIDON, E.; SHEARD, P. R.; ENSER, M. Effect of fatty acids on meat quality: a review. Meat Science, Amsterdan, v. 66, p. 21-32, 2003. 
YAMAMOTO, S.M. Desempenho e características da carcaça e da carne de cordeiros terminados em confinamento com dietas contendo silagens de resíduos de peixes. Jaboticabal: Universidade Estadual Paulista, 2006. 95p. Tese (Doutorado em Zootecnia) - Universidade Estadual Paulista, 2006.

ZEOLA, N.M.B.L; SILVA SOBRINHO, A.G.S.; MANZI, G. M. Desempenho e características da carcaça de cordeiros submetidos aos modelos de produção orgânico e convencional.Arq. Bras. Med. Vet. Zootec., v.63, n.1, p.180-187, 2011. 